\title{
Paylaşım Ekonomisinde Mülk Paylaşma Hizmetlerine Duyulan Güvenin Rolünü Tüketici Perspektifinden İnceleme: Airbnb Örneği \\ (Examining The Role of Trust in Property Sharing Services in The Share Economy From a Consumer Perspective: The Case of Airbnb)
}

\section{Tuğçe ASLAN iD a , Adem AKBIYIK iD b}

aDüzce Üniversitesi, İşletme Fakültesi, Yönetim Bilişim Sistemleri Bölümü, Düzce, Türkiye. tugceaslan@duzce.edu.tr bSakarya Üniversitesi, İşletme Fakültesi, Yönetim Bilişim Sistemleri Bölümü, Sakarya, Türkiye. adema@sakarya.edu.tr

\begin{tabular}{|c|c|}
\hline MAKALE BİLGİSİ & ÖZET \\
\hline $\begin{array}{l}\text { Paylaşım Ekonomisi } \\
\text { İşbirlikçi Tüketim } \\
\text { Yapısal Eşitlik Modeli } \\
\text { Güven }\end{array}$ & $\begin{array}{l}\text { Amaç - Fiziksel ortamlarda gerçekleşen geleneksel paylaşım dijital ortama taşınarak paylaşım } \\
\text { ekonomisi adı altında yeni bir iş modeli doğurmuştur. Bu ekonomik sistemin tüketiciye yansıması } \\
\text { hem uygulayıcılar hem araştırmacılar için ilgi çekici bir çalışma alanı olmuştur. Çalışmanın temel } \\
\text { amacı çevrimiçi veya mobil paylaşım hizmetlerine duyulan güvenin rolünü tüketicilerin bakş̧ } \\
\text { açısıyla araştırmaktır. Bu amaç doğrultusunda, çevrimiçi hizmetlere güvenin paylaşma eylemini } \\
\text { gerçekleştirmek için gerekli(önemli) bir şey olduğunun doğrulanması istenmektedir. }\end{array}$ \\
\hline $\begin{array}{l}\text { Gönderilme Tarihi } 20 \text { Ağustos } \\
2019 \\
\text { Revizyon Tarihi } 17 \text { Eylül } 2019\end{array}$ & $\begin{array}{l}\text { Yöntem - Paylaşım hizmeti sunan platformlar arasından Airbnb seçilerek ölçek hazırlanmıştır. } 150 \\
\text { katılımcıdan elde edilen nicel veriler SPSS programına aktarılmıştır. Daha sonra Smart PLS } \\
\text { programı ile önerilen kuramsal model test edilmiştir. Modeli test etmek için, Yapısal Eşitlik Modeli } \\
\text { (YEM) yaklaşımı kullanılmıştır. }\end{array}$ \\
\hline Kabul Tarihi 20 Eylül 2019 & $\begin{array}{l}\text { Bulgular - Elde edilen bulgulara göre, Airbnb platformunun ünü, Airbnb'ye güveni ve Airbnb'ye } \\
\text { duyulan güvenin, mülk sahiplerine duyulan güveni yüksek derecede etkilediği tespit edilmiştir. Ek } \\
\text { olarak, Airbnb'ye güvenin Airbnb'yi kullanma niyetini yüksek derecede etkilediği bulunmuştur. }\end{array}$ \\
\hline Araştırma Makalesi & $\begin{array}{l}\text { Tartışma - Bu çalışmadan elde edilen sonuçlara göre, Türkiye'de uluslararası markalaşmış veya ünü } \\
\text { olan platformlara güven yüksekken o markaya hizmet veren hizmet sağlayıcılarına güvenin görece } \\
\text { düşük olduğu gözlemlenmiştir. Bu durum Türkiye'de paylaşım hizmeti sunacak girişimcilerin hem } \\
\text { ün kazanma, hem de hizmet sağlayıcılara güveni kazanmak adına farklı çalışmalar yapması } \\
\text { gerektiğini ortaya koymaktadır. }\end{array}$ \\
\hline
\end{tabular}

\begin{tabular}{|c|c|}
\hline ARTICLE INFO & ABSTRACT \\
\hline Keywords: & $\begin{array}{l}\text { Purpose- The main purpose of this study is to compare the relationship between organizational } \\
\text { cynicism and intention to quit of public and private sector. }\end{array}$ \\
\hline $\begin{array}{l}\text { Collaborative Consumption } \\
\text { Structural Equation Model } \\
\text { Trust }\end{array}$ & $\begin{array}{l}\text { Design/methodology/approach- The population of the study includes the private security officers } \\
\text { working in Ankara. Random sampling is conducted in the study. As a result of questionnaires, } 2249 \\
\text { data were found analyzable. In this study, the Organizational Cynicism Scale developed by Brandes, } \\
\text { Dhalwadkar and Dean (1999) and Intention to Quit Scale developed by Scott et all (1999) was used. } \\
\text { T-Test and Regression analysis was used in data analysis. }\end{array}$ \\
\hline Revised 17 September 2019 & $\begin{array}{l}\text { Findings- According to the result of the study, it was revealed that there is a positive relationship } \\
\text { between organizational cynicism and intent to quit, and the relationship between them differs } \\
\text { according to private security officers' employment type. }\end{array}$ \\
\hline $\begin{array}{l}\text { Article Classification: } \\
\text { Research Article }\end{array}$ & $\begin{array}{l}\text { Discussion- Research results show that the perception of organizational cynicism is more effective } \\
\text { on the intention to quit for private security officers employed in the private sector. Ways of } \\
\text { struggling with organizational cynicism are indicated. }\end{array}$ \\
\hline
\end{tabular}




\section{Giriş}

Bilgi ve iletişim teknolojilerindeki gelişmeler kullanıcılar ile bilgi sistemleri arasındaki bilgi asimetrisini azaltarak işletmelerin geleneksel iş modellerinden uzaklaşmasına yol açmıştır. Tüm dünyada yaşanan dijital dönüşüm süreci, işletmeleri daha yenilikçi iş modellerine yöneltmiştir. Günümüzde gittikçe yaygınlaşan bu iş modellerinden biri de paylaşım ekonomisidir. Paylaşım ekonomisi(PE), dijital platformlar aracılığıyla az kullanılmış ya da hiç kullanılmamış bir ürün veya hizmetin ihtiyacı olan başka birine kiralanması ve sunulmasını içeren bir alışveriş şeklidir.

Bugün iletişim teknolojileri ve internet erişiminin yaygınlaşması tüketicileri neredeyse sürekli olarak çevrimiçi hale getirmiştir. Dolayısıyla teknoloji, sadece satın almakla kalmayıp sosyal ağ bağlantılarına dayanan güncel bir paylaşım şekli olan "Paylaşım Ekonomisi" olarak adlandırılan yeni paylaşım modelini geliştirmenin en kolay yolu olmuştur (Botsman \& Rogers, 2010 s.67). Modern bilgi teknolojisinin kullanılması paylaşım ekonomisini geleneksel paylaşımdan ayıran en temel farktır (Zvolska, 2015 s.18).

Paylaşım ekonomisi ilk ortaya çıktığı zamanlarda sadece geçici bir heves olarak düşünülmekteydi fakat şimdi son derece güçlü bir olgu haline gelmektedir. Yapılan bir araştırmaya göre paylaşım ekonomisi sektörünün, 2025 yılına kadar 335 milyar dolar değerinde olması beklenmektedir (Statista, 2018b). Bundan dolayı paylaşım ekonomisi sektörü yatırımcıların ve geliştiricilerin ilgisini çekmektedir. Bu noktada firmalar ve uygulamacılar, sektörde başarılı olabilmek ve rekabet avantajı elde etmek için potansiyel kullanıcıların istek ve ihtiyaçlarını doğru analiz ederek etkili stratejiler geliştirmek durumundadır. Fakat bu konuda Türkiye'de yapılan çalışmalar son dönemlerde artış göstermesine rağmen toplumun çevrimiçi paylaşım hizmetlerini nasıl benimsedikleri ve nasıl algıladıklarına yönelik çalışmalara ihtiyaç olduğu düşünülmektedir.

Teknolojik gelişmelerin oldukça hızlı yaşanması ve bireylerin yoğun bir enformasyon altında kalması dijital ortamlara olan güveni etkilemektedir. Dijital ortama duyulan güven ise çevrimiçi veya mobil platformlar aracılığıyla sunulan paylaşım hizmetlerine katılma ve kullanma kararlarını etkilemektedir. 2012 yılında yapılan bir araştırmaya göre (Davis, 2012); katılımcıların \% 67'si, işbirlikçi tüketim hizmetine katılmanın önündeki başlıca engelin güven sorunu olduğunu, eşyaların kırılmasından veya çalınacağından endişe duyduklarını ifade etmişlerdir. PwC raporuna göre güven, paylaşım platformlarının temel taşıdır (PwC, 2015 s.5) ve güven olmadığı takdirde bir paylaşım platformu işlemeyecektir (Tosuner, 2012 s. 9).

Bu çalışmada, Türkiye'de paylaşım hizmetlerine katılımı etkileyen güven faktörleri detaylı bir biçimde tartışılmaktadır. Bu kapsamda çevrimiçi veya mobil paylaşım hizmetlerine duyulan güven, paylaşım ekonomisine katılımı nasıl etkiler? sorusuna cevap aranacaktır.

Çalışma sonuçları, paylaşım uygulamaları hakkında tüketici bilgi asimetrisini azaltarak, çevrimiçi veya mobil paylaşım hizmetlerinin benimsenmesi sağlamak için mevcut sorunların belirlenmesinde önemli bir rol oynayacaktır. Ayrıca çalışmanın, yeni ekonomik sistem hakkındaki bilimsel eksiklikleri de doldurması beklenmektedir.

\section{Kavramsal Altyap1 Paylaşım Ekonomisi}

Tarih boyunca insanlar savaşlar, doğal felaketler ve toplumsal kargaşalar gibi olumsuz koşullarda herkesin hayatta kalma şansını arttırmak için ellerindeki kaynaklarını bir araya getirme eğilimi göstermiştir. Bu şekilde insanlar arasında paylaşım faaliyetleri başlamıştır. Son yıllarda baş gösteren ekonomik bunalımlar, artan tüketim, azalmakta olan yenilebilir enerji kaynakları ve gelişen teknoloji gibi bir dizi faktör geleneksel paylaşım kalıplarının değişmesine yol açmıştır.

Özellikle bilgi ve iletişim teknolojilerindeki (BİT) yaşanan gelişmeler, kullanıcılar ve bilgi sistemleri arasında sürekli veri alışverişine yol açarak yeni dağıtım kanallarının ortaya çıkmasını sağlamıştır. İnternete sürekli bağlı olan akıllı telefonlar ve diğer cihazlar, herhangi bir bireyin gerçek zamanlı olarak başkalarıyla işbirliği yapmasına olanak tanımıştır (Gyódi, 2017 s.2). Bilhassa, Web 2.0 teknolojisinin gelişi ile birçok yeni paylaşım modelleri ortaya çıkmıştır. İnsanların sosyal teknolojileri kullanarak mal ve hizmetlerini paylaşma fikri, paylaşım ekonomisi çağını başlatmıştır.

Günümüzde internetin, çevrimiçi sosyal ağların ve mobil teknolojilerin yaygınlaşması ile en önemli değişimin bireylerin tüketim alışkanlıklarında olduğu görülebilmektedir. Yaşanan bu süreç mülk sahiplerinin mallarını 
arkadaşlarıyla, komşularıyla ve hatta yabancılarla kolaylıkla paylaşmalarını mümkün kılmıştır. Paylaşım Ekonomisi, teknolojik gelişmeleri bir arada tutan bir çeşit şemsiye olarak görülebilir. Bireyler sahip oldukları kullanılmamış ya da az kullanılmış varlıkları üretken kaynaklara dönüştürmek için dijital platformları kullanmaktadır.

Günümüzde hızla büyüyen ve yoğun bir şekilde tartışılan bir olgu olarak "Paylaşım Ekonomisi" kavramı ilk kez 2008 yılında Harvard Hukuk Okulu'nda Profesör Lawrence Lessig tarafından kullanılmıştır (Kim ve diğ, 2015 s. 1). İlerleyen zamanlarda dünya çapında yayılan bir ekonomi türü olmasına rağmen, paylaşım ekonomisinin ortak bir tanımı bulunmamaktadır (Hou, 2018 s.2). Akademik literatürde yer alan bazı tanımlamalar şunlardır:

Botsman (2013 4)'a göre paylaşım ekonomisi, ürün ve hizmetlerin paylaşılması, takası, ticareti veya kiralanmasına dayanan ve mülkiyete erişimi sağlayan internet aracılı bir ekonomik modeldir. Mair \& Reischauer (2017 s.2)'ye göre, paylaşım ekonomisi, bir kuruluş tarafından işletilen dijital bir platformun aracılık ettiği kaynakların yeniden dağıtımını sağlama ve kaynaklara erişimi gerçekleştirmek için çeşitli ödeme biçimlerinin kullanıldığı bir pazar ağıdır.

Paylaşım ekonomisi terimi etrafında devam eden anlaşmazlıklara rağmen, 2015 yılında Oxford sözlüğüne, "bireyler arasında varlıkların veya hizmetlerin genellikle internet aracılığıyla ücretli veya ücretsiz paylaşıldığı bir ekonomik sistem" tanımıyla girmiştir (Oxford Dictionary, 2018 1; Parente ve diğ, 2018 s.53).

Paylaşım ekonomisi kavramı aynı zamanda işbirlikçi tüketim olarak da adlandırılmaktadır (Hamari ve diğg., 2015 s.3). İşbirlikçi tüketim kısaca bir kaynağın ücret veya başka bir tür karşılık için alınması ve dağıtılması olarak tanımlanabilir (Conte, 2016 s.10). Daha geniş bir tanımla ifade etmek gerekirse mekân, ürün, zaman ve beceriler de dâhil olmak üzere bireylerin varlıklarını paylaşma, ödünç verme veya takas etme gibi sosyoekonomik hareketlerini kapsayan bir terimdir (Mun, 2013 s.8). Botsman (2013 16)' a göre ise işbirlikçi tüketim; birbirleriyle bağlantı içindeki bireylerin ve toplulukların, merkezileşmiş kurumlara karşı üretme, tüketme finanse etme ve öğrenme biçimini değiştirerek ekonominin bir parçasını oluşturmaktadır.

Paylaşım ekonomisinin neden ortaya çıtığı ve nasıl geliştiğine dair kesin bir görüş belirtilmemesine rağmen, ortaya çıkmasına ilişkin ışık tutan çeşitli araştırmacıların önerileri vardır. Belk (2014 s.1595), İşbirlikçi tüketim ve paylaşım ekonomisi kavramlarının internetle birlikte ortaya çıktığını savunmaktadır. Bunula birlikte, araştırmacıların büyük bir çoğunluğu somut kanıt olmamakla paylaşım ekonomisinin ortaya çıkışında teknolojinin yanı sıra 2008'de başlayan ekonomik krizin etkisi olduğunu savunmaktadır (Kosintceva, 2016 s.9). Bu kriz birçok kişinin evini, arabasını ve yatırımlarını kaybetmesine neden olmuştur. Mali zorluklarla karşı karşıya kalan insanlar tüketim alışkanlıklarını değiştirmek için bir arayış içerisine girmiştir Krizden itibaren insanlar mal ve hizmetleri satın almak yerine, geçici olarak erişim sağlayacağı paylaşım modellerine yönelmişlerdir.

Küresel ısınma, artan yakıt kullanımı ve hammadde fiyatları, artan çevresel kirlilik ve diğer toplumsal sorunlar, paylaşım ve işbirliğine dayalı tüketimi tetikleyen diğer faktörlerdir. Sonuç olarak paylaşım ekonomisi, aşırı tüketim, çevresel kirlilik ve yoksulluk gibi birçok soruna yanıt olarak doğmuştur. Paylaşım hizmetlerinin yayılmasının küresel olarak büyük bir toplumsal etkiye neden olacağı ve bu nedenle araştırmacılar ve uygulayıcılar için ilgi odağı haline geleceği tahmin edilmektedir (Hamari ve diğg., 2015 s.2).

\section{Dijital Dünyada Güven}

Her bilim güven kavramını kendi çerçevesinde ele almış ve kavram birçok farklı şekilde tanımlanmıştır. Güven, genellikle herkes tarafından anlaşılan, ancak açıklanması ve tanımlanması zor olan bir kavramdır (Demircan \& Ceylan, 2003 s.141). Bu durum, güven kavramının ortak bir tanımlanmasının yapılmasını ve açıklanmasını oldukça zorlaştırmıştır. Yapılan çalışmalar incelediğinde güven kavramı hakkında yapılan tanımlar şu şekildedir;

Giffin (1967 s.104) güveni, riskli bir durumda istenen bir hedefe ulaşmak için sorgulamadan bir başkasına veya bir şeye olan inanç olarak tanımlamıştır. Başka bir tanımlamada güven kavramı kişinin kendine güveni olan bir değişim partnerine güvenme isteği olarak ifade edilmektedir (Moorman, Deshpandé, \& Zaltman, 1993 s.82). 
Mölmann (2015 s.193) yaptığı çalışmada ise güvenin hem hizmetin kullanılmasına olan istekliliğini etkilediğini hem de tüketimin tatmini üzerinde büyük bir etkiye sahip olduğunu ve tüketicinin yeniden hizmet seçme olasılığını etkilediğini ortaya çıkarmıştır.

Çevrimiçi güven ise, müşteri ile internet arasındaki güveni kapsamasından dolayı genel güvenden ayrılmaktadır (Bart, Shankar, Sultan, \& Urban, 2005 s.134).Geleneksel yüz yüze etkileşimin aksine, tüketiciler ve firmalar arasındaki birincil arayüz çevrimiçi ortamdır. Bu nedenle, tüketicilerin çevrimiçi firmalarla pozitif ilişkiler geliştirmesi için öncelikle çevrimiçi ortama ya da internet teknolojilerine duyulan güven oluşmuş olmalidir (Ye, 2013 s.7).

Literatürde yer alan önceki çalışmaların bazıları çevrimiçi güveni, teknolojiye duyulan güven olarak tanımlamıştır (Ratnasingam, 2004 d. 526). Teknolojiye duyulan güven ile insanlara duyulan güven birbirinden farklıdır. Sosyal güven çoğunlukla güvenin kurulmasının daha kolay olduğu yüz yüze etkileşimlere ve ilişkilere dayanır. Çevrimiçi güven ise, sanal ortama dayandığı için karmaşık bir konudur. Tüketiciler bir web sitesiyle etkileşimde rahat hissettiklerinde, web sitesine güven geliştirebilirler ve güven, belirsizlik ve korkuyla başa çıkmak için temel strateji haline gelmektedir (Jarvenpaa, Tractinsky, \& Saarinen, 2000 s.46).

Çevrimiçi ortama duyulan güvenin gelişmesi paylaşım ekonomisi hizmetlerinin başarısı açısından önemlidir. Çünkü tüketicinin çevrimiçi ortama olan güveni paylaşım hizmetlerine duyulan güvenini de etkileyecektir (Finley, 2012 s.16). Yapılan bir araştırmada tüketicinin güveninin, çevrimiçi ortamda işlem yapma niyeti üzerinde doğrudan olumlu bir etkiye sahip olduğu kanıtlanmıştır (Kim, Ferrin, \& Rao, 2009 s.556).

Chung ve diğerleri (2010, s.485) çalışmasında, web sitesi tasarımı gibi web sitesinin özelliklerine ilişkin bakış açlarının, platformu kullanma niyetini etkileyebildiğini belirtmiştir. Diğer bir deyişle çevrimiçi platformun kullanım kolaylığı ve algılanan güvenlik kontrolü güven oluşumu üzerinde önemli bir etkiye sahiptir (Koufaris \& Hampton-Sosa, 2004 s.379).

Çevrimiçi ortamda alışveriş yapan tüketiciler çoğunlukla güvenliğe bağlı olan ödeme riski veya kişisel risk ile çok ilgilidir. Liao ve Cheung (2002 s.293) çalışmasında internet tabanlı e-bankacılığa yönelik tutumlar araştırılmış ve sistem güvenliğinin, sistem kullanımına yönelik müşteri tutumlarının önemli bir belirleyicisi olduğu bulunmuştur. Başka bir çalışmada ise web sitesinin algilanan kalitesinin, güven üzerinde olumlu bir etkiye sahip olduğu bulunmuştur (Jones \& Leonard, 2008 s.94). Diğer bir çalışmaya göre, web sitesi tasarımı kalitesinin mağaza itibarından daha önemli olduğunu bulunmuştur (Liang \& Lai, 2002 s.443). Buradan hareketle bir şirketin web sitesine güven, müşterilerin şirkete karşı tutumlarını ve satın alma isteklerini etkilemektedir yorumu yapılabilir.

Ek olarak her bireyin güvenme eğilimi farklıdır. Bazı bireylerin karşı tarafa güvenme olasılı̆̆ı daha yüksektir (Gefen, 2000 s.726). Bunun sebebi çevrimiçi alışverişlerden edinilen deneyim ve tecrübelerin kişiden kişiye farklılık göstermesidir. Yapılan alışverişten edilen deneyimler kişinin güvenme eğilimini pozitif ya da negatif yönden etkilemektedir. Çevrimiçi alışverişlere aşina olan anlayışlı bir müşterinin, çevrimiçi satıcılara güvenme olasılığı daha yüksek olacaktır (Weisberg, Te'eni, \& Arman, 2011 s.82). Buna ek olarak, tüketicilerin güven derecesi ne kadar yüksek olursa, satın alma niyeti de o kadar yüksek olmaktadır ve düşük seviyedeki tüketici güveni, kişilerin çevrimiçi alışverişten kaçınmasının temel nedenidir (Gefen \& Straub, 2004 s.410).

Airbnb

2008 yılında Amerika'da kurulan Airbnb, paylaşım ekonomisi sektörünün asıl başarısını gösteren sayılı şirketlerden biridir. Konaklama paylaşımında büyük başarı elde eden Airbnb, bireylere kısa süreli konaklama imkanı sağlamaktadır. Bireyler sisteme hem sağlayıcı hem tüketici olarak dahil olabilmektedir. Bugün 81.000 den fazla şehirde ve 191 ülkede hizmet vermektedir (Airbnb, 2018 1). Şirketin mevcut değerinin 2017 yılında 31 milyar dolar olduğu söylenmektedir (Forbes, 2018 1). Sektördeki benzer uygulamalar ise Couchsurfing \& Homeaway'dir. 


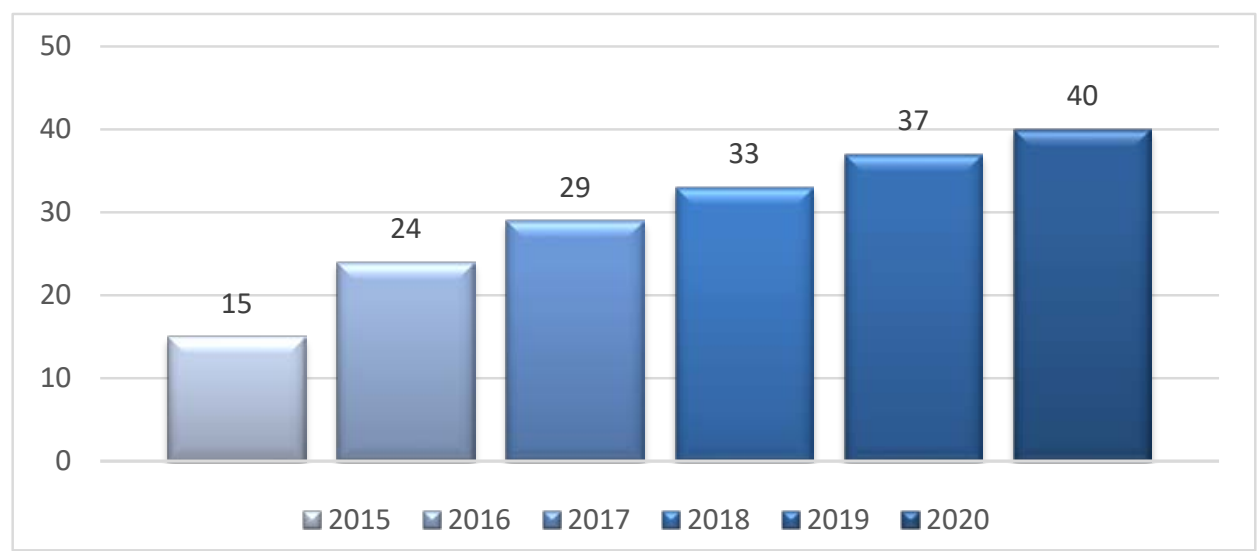

Grafik 1: Yıllara Göre Avrupa ve Amerika'da Airbnb Kullanıcı Sayısı (Milyon) Kaynak:(Statista, 2018a)

2018 yılında Avrupa ve Amerika' da 33 milyon kişi Airbnb platformundan yararlanmıştır. Bu sayının 2019 yılı sonunda 37 milyon, 2020 yılı sonunda ise 40 milyon olması beklenmektedir.

\section{Yöntem}

Araştırma probleminin çözümü için en uygun yöntemin nicel araştırma yöntemleri olduğu uygun görülmüştür. Verilerin toplanmasında anket tekniği kullanılmıştır. Yapılan araştırmalar ve ilgili literatür göz önünde bulundurulduğunda verilerin analizi için yapısal eşitlik modeli yaklaşımı uygun görülmüştür. Evren, araştırma sonuçlarının genellendiği büyük gruptur. Örneklem ise evren hakkında genellemeler yapmak adına evreni temsil eden evren içinden seçilen küçük kümedir (Altunışık ve diğ., 2002 s.56). Maliyet, zaman ve veri analizi şartlarını dikkate alındığında araştırma örneklemi için kolayda örneklem yöntemine karar verilmiştir. Kolayda örneklem yöntemi bilimsel araştırmalarda oldukça yaygın kullanılan bir tekniktir. Uygun örneklem olarak da bilinen kolayda örnekleme tekniğinde araştırmacı, çalışması için ihtiyaç duyduğu büyüklükteki örnekleme ulaşıncaya kadar en kolay ve ulaşılabilir deneklerden veri toplamaya çalışır ve ankete cevap veren herkes örneğe dahil edilmektedir. Kolayda örnekleme tekniği diğer tekniklere kıyasla yapılması daha kolay, hızlı ve ucuzdur (Altunışık ve diğ., 2002 s.63).

Katılımcılara kolayca ulaşılabilmesi amacıyla araştırma, online platformlar aracılığıyla gerçekleştirilmiştir. Anket çalışması olasılığa dayalı olmayan örneklem çeşitlerinden kolayda örneklem yöntemi kullanılarak Google formlar üzerinden ve elden 05/01/2019-10/04/2019 tarihler arasında toplanmıştır. Zaman ve maliyet kısıtları nedeniyle belirlenen zaman diliminde toplamda 150 kişi araştırmaya katılmıştır.

\subsection{Araştırma Modeli ve Hipotezleri}

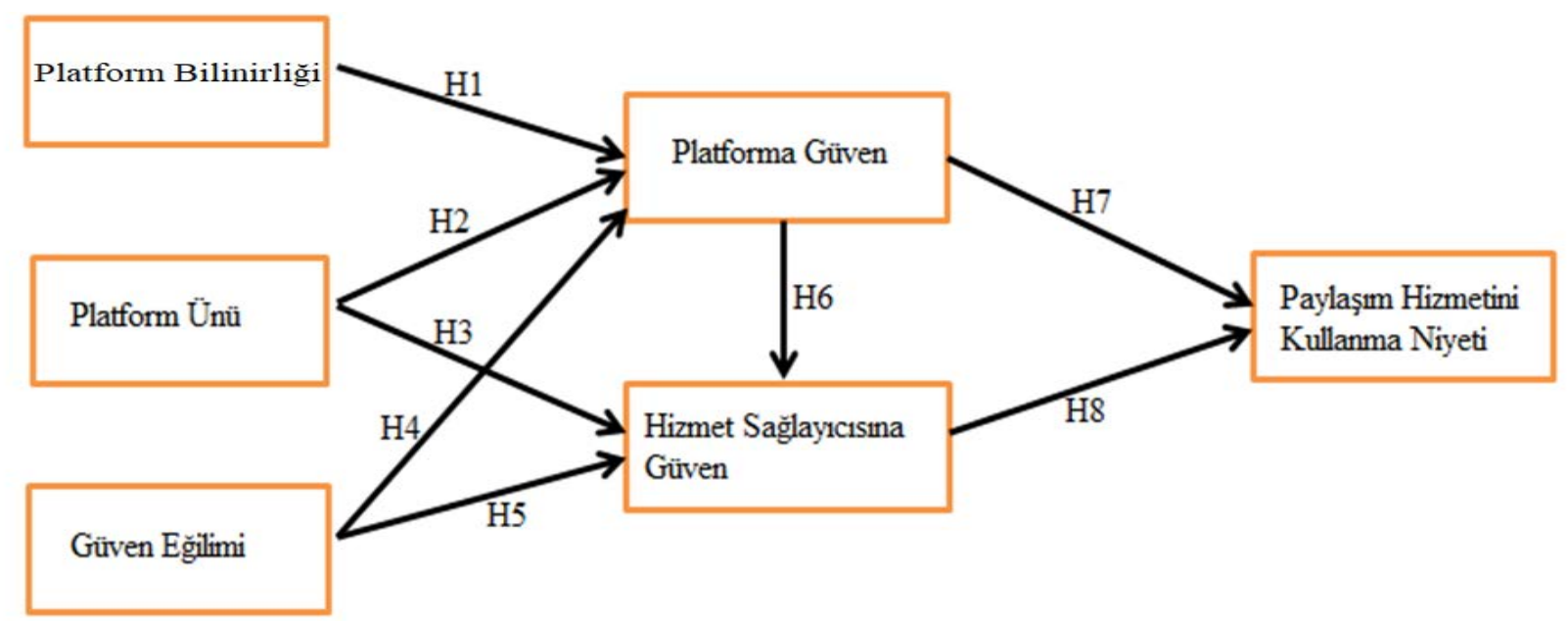

Şekil 1: Araştırma Modeli Kaynak: Gao, Jing, \& Guo, 2017 s.4

$\mathrm{Bu}$ modelde araştırmanın konusunu oluşturan değişkenler ve bu değişkenler arasındaki, ilişkiler gösterilmiştir. Değişkenler arasındaki oklar değişkenler arasındaki ilişkinin yönünü göstermektedir. Ayrıca çizilmiş olan bu oklar çalışmanın hipotezlerini oluşturmaktadır. 


\section{Bulgular}

Kolayda örnekleme yöntemi ile elde edilen veri setine dair tanımlayıcı bilgiler ve araştırma modeline ait analizler aşağıda sunulmuştur.

Tablo 1. Örnekleme Ait Tanımlayıcı İstatistikler

\begin{tabular}{|c|c|c|c|}
\hline Değişken Adı & Değişken Değeri & F & $\%$ \\
\hline \multirow{3}{*}{ Cinsiyet } & Kadın & 68 & 45,3 \\
\hline & Erkek & 82 & 54,7 \\
\hline & Toplam & 150 & 100,0 \\
\hline \multirow{3}{*}{ Medeni Durum } & Evli & 40 & 26,7 \\
\hline & Bekar & 110 & 73,3 \\
\hline & Toplam & 150 & 100,0 \\
\hline \multirow{7}{*}{ Eğitim Durumu } & İlkokul & 2 & 1,3 \\
\hline & Lise & 13 & 8,7 \\
\hline & Ön Lisans & 9 & 6,0 \\
\hline & Lisans & 87 & 58,0 \\
\hline & Yüksek Lisans & 25 & 16,7 \\
\hline & Doktora & 14 & 9,3 \\
\hline & Toplam & 150 & 100,0 \\
\hline \multirow{7}{*}{ Gelir Durumu } & $1000 \mathrm{Tl}^{\prime}$ den az & 66 & 44,0 \\
\hline & $1001 \mathrm{TL}-2500 \mathrm{TL}$ & 20 & 13,3 \\
\hline & $2501 \mathrm{TL}-4000 \mathrm{TL}$ & 22 & 14,7 \\
\hline & $4001 \mathrm{TL}-5500 \mathrm{TL}$ & 17 & 11,3 \\
\hline & $5501 \mathrm{TL}-7000 \mathrm{TL}$ & 20 & 13,3 \\
\hline & 7001 TL ve üzeri & 5 & 3,3 \\
\hline & Toplam & 150 & 100,0 \\
\hline
\end{tabular}

Tablo 1 incelendiğinde, \%45 kadın, \%54 erkek katılımcılardan oluşmaktadır. Medeni duruma bakıldığında; \%26'sı evli, \%73'ü bekâr olarak dağılmaktadır. Katılımcıların eğitim durumlarına bakıldığında; \%1'i İlkokul, $\% 8^{\prime} i$ lise, \%6'i ön lisans, \%58'i lisans, \%16's1 yüksek lisans ve \%9'unun doktora seviyesinde olduğu görülmektedir. Katılımcıların gelir durumlarına bakıldığında ise; \%44'ü 1000 TL' den az, \%13'ü 1001 TL ile 2500 TL arası, \%14'ü 2501 TL ile 4000 TL arası, \%11'i 4001 TL ile 5500 TL arası, \%13'ü 5501 TL ile 7000 TL aras1 ve \%3'i 7001 TL ve üzeri olduğu görülmektedir.

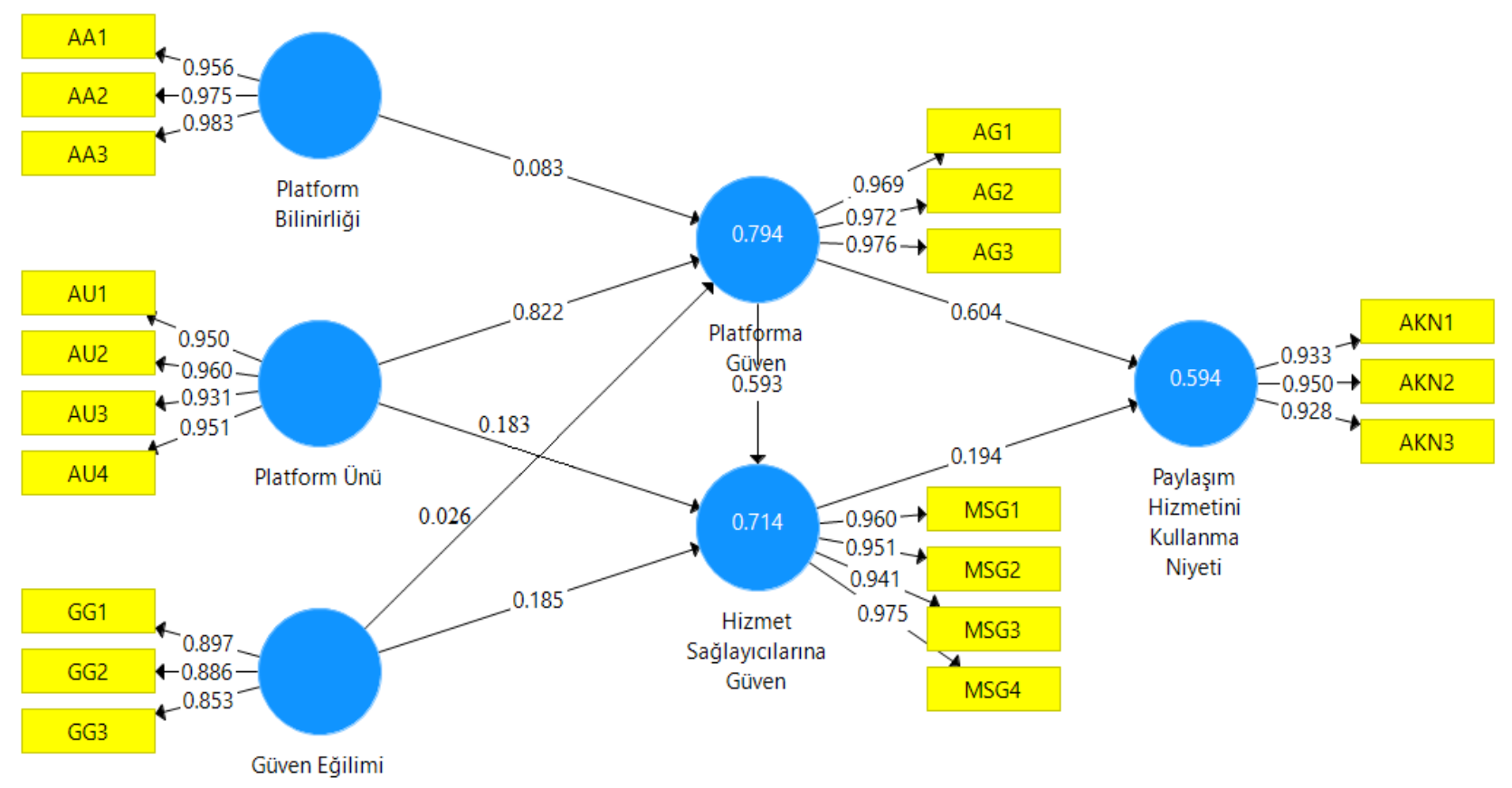

Şekil 2: Araştırma Modeli Analiz Sonuçları 
Şekil 2' deki sonuçlara göre platform bilinirliği, platforma güven üzerindeki değişimin \%8'ini açılamaktadır. Platform ünü, platforma güven üzerindeki değişimin \%82'sini, hizmet sağlayıcısına güven üzerindeki değişimin \%18'ini açıklamaktadır. Güven eğilimi, platforma güven üzerindeki değişimin \%2'sini, hizmet sağlayıcısına güven üzerindeki değişimin \%18'ini açıklamaktadır. Platforma güven, hizmet sağlayıcısına güven üzerindeki değişimin $\% 59^{\prime}$ unu, paylaşım hizmetini kullanma niyeti üzerindeki değişimin \%60'ını açıklamaktadır. Hizmet sağlayıcısına güven, paylaşım hizmetini kullanma niyeti üzerindeki değişimin \%19'unu açıklamaktadır. Genel olarak bu model, Airbnb paylaşım hizmetini kullanma niyetini \%59 oranında açılamaktadır.

Yapısal eşitlik model uygulamaları, test edilen modelin o model için toplanmış veri seti ile ne derecede uygun olduğuna dair uyum indeksleri sunar. Modelin kabul edilmesi veya reddedilmesi kararının alınmasında bu uyum iyiliği ölçüleri kullanılmaktadır. Model uygunluğunun değerlendirilmesinde kullanılan uyum indeksleri analizin yapıldığı programa göre değişmektedir. Bu çalışmada SMART PLS programı tarafından hesaplanan SRMR VE NNF uyum değerleri üzerinden yorumlamalar yapılacaktır. SRMR değerinin 0.08 ve altında olması modelin kabul edilebilirliğine işarettir (Gürbüz \& Şahin, 2016 s.337). NNF değerinin 0,90 ve üzeri olması iyi uyumu, 0,95 ve üzeri olması ise mükemmel uyumu göstermektedir (Ateş, 2014 s.89). Temelde değerin 1'e yaklaşması mükemmel uyuma, 0'a yaklaşması ise model uyumsuzluğuna karşılık gelir (Cokluk ve diğ., 2010 s. 270).

Tablo 2'de araştırma modelinin uyum indeksleri sunulmaktadır.

Tablo 2. Model Uyum İndeksleri

\begin{tabular}{|l|l|l|}
\hline & SRMR & NNF \\
\hline Airbnb & 0.042 & 0.876 \\
\hline
\end{tabular}

Tablo 2 ‘ye göre araştırma ölçeklerinin uyum iyiliği indekslerine bakıldığında; üç paylaşım hizmeti için SRMR değerlerinin $0.042,0.041,0.047$ ve NNF değerlerinin $0.876,0.874,0.877$ olduğu görülmektedir. Bu sonuçlara göre, modelin kabul edilebilir olduğu söylenebilmektedir.

Smart PLS paket programı güvenilirliğin hesaplanmasında Cronbach Alfa, bileşik güvenilirlik (CR) ve hesaplanan ortalama varyans değerinden (AVE) faydalanılmaktadır. Cronbach Alfa değerinin 0,70'in üstünde, $C R$ değerinin 0,70'in üstünde ve AVE değeri 0,50'nin üstünde olduğunda ölçek güvenilirliğinden söz edilebilmektedir (Öngel, 2018 s.59). Airbnb ölçeği için güvenilirlik değerleri Tablo 3 `de sunulmaktadır.

Tablo 3. Ölçeğe Ait Güvenilirlik Değerleri

\begin{tabular}{|l|c|c|c|}
\hline & $\begin{array}{c}\text { Gizil(Örtük) } \\
\text { Değisken Adı }\end{array}$ & $\begin{array}{c}\text { Cronbach's } \\
\text { Alpha }\end{array}$ & $\begin{array}{c}\text { Composite } \\
\text { Reliabilitv(CR) }\end{array}$ \\
\hline Platform Bilinirliği & 0.970 & 0.980 & 0.943 \\
\hline Güven Eğilimi & 0.852 & 0.910 & 0.772 \\
\hline Platform Ünü & 0.962 & 0.973 & 0.899 \\
\hline Platforma Güven & 0.971 & 0.981 & 0.946 \\
\hline Hizmet Sağlayıcılarına Güven & 0.969 & 0.977 & 0.915 \\
\hline Paylaşım Hizmetini Kullanma Niyeti & 0.931 & 0.956 & 0.878 \\
\hline
\end{tabular}

Tablo 3 incelendiğinde, gizil(örtük) değişkenlere ait güvenilirlik değerlerinin tamamının 0,70 değerinin üstünde olduğu görülmektedir. Buna göre, modelde kullanılan bütün örtük değişkenlerin güvenilir olduğunu dolayısıyla bu araştırma için oluşturulan modelin istatistiksel olarak anlamlı ve güvenilir olduğunu söyleyebiliriz.

Faktör analizi sonucu ortaya çıkan her bir maddeye ilişkin faktör yükleri Tablo 4' de yer almaktadır. 
Tablo 4. Faktör Yükleri

\begin{tabular}{|c|c|c|}
\hline & Değişken Adı & Faktör Yükü \\
\hline \multirow[t]{3}{*}{ Güven Eğilimi } & Genelde insanlığa inancım var. & 0.897 \\
\hline & İnsanların genelde güvenilir olduğunu hissediyorum & 0.886 \\
\hline & Genelde bir sebep olmadıkça diğer insanlara güvenirim. & 0.853 \\
\hline \multirow{3}{*}{$\begin{array}{l}\text { Platform } \\
\text { Bilinirliği }\end{array}$} & Airbnb hakkında bilgiye sahibim. & 0.956 \\
\hline & Airbnb uygulamasının fonksiyonları hakkında bilgiye sahibim. & 0.975 \\
\hline & Airbnb’nin hizmetleri hakkında bilgiye sahibim. & 0.983 \\
\hline \multirow[t]{4}{*}{ Platform Ünü } & Airbnb sektörde saygı görmektedir. & 0.950 \\
\hline & Airbnb saygın bir firmadır. & 0.960 \\
\hline & Airbnb sektörde iyi bir üne sahiptir. & 0.931 \\
\hline & Airbnb doğruluk imajına sahiptir. & 0.951 \\
\hline \multirow[t]{3}{*}{ Platforma Güven } & Airbnb’nin sağladığı bilgiye inanıyorum. & 0.969 \\
\hline & Airbnb'nin güvenilir olduğuna inanıorum. & 0.972 \\
\hline & Airbnb'ye güvenirim. & 0.976 \\
\hline \multirow{4}{*}{$\begin{array}{l}\text { Mülk Sahiplerine } \\
\text { Güven }\end{array}$} & Mülk sahipleri genelde güvenilirdir. & 0.960 \\
\hline & Mülk sahipleri genelde dürüsttür. & 0.951 \\
\hline & Potansiyel Mülk sahiplerine güveniyorum. & 0.941 \\
\hline & Mülk sahiplerin güvenilir olduğuna inanıyorum. & 0.975 \\
\hline \multirow{3}{*}{$\begin{array}{l}\text { Airbnb Kullanma } \\
\text { Niyeti }\end{array}$} & Yakın zamanda Airbnb uygulamasını kullanmayı istiyorum. & 0.933 \\
\hline & Uzun bir süre Airbnb uygulaması hizmetlerinden yararlanacağım. & 0.950 \\
\hline & Airbnb uygulamasını arkadaşlarıma ve aileme tavsiye edebilirim. & 0.928 \\
\hline
\end{tabular}

Sosyal bilimlerde faktör yüklerinin 0,40'tan yüksek olması yeterli kabul edilmektedir (Yeşilyurt, 2018: 139). Tablo 4 incelendiğinde faktör yüklerinin 0,853 ve üzerinde olduğu görülmektedir. Bu durum ölçek geçerliliğini doğrulamaktadır.

Tablo 5. Hipotez Testti

\begin{tabular}{|l|l|c|c|}
\hline \multicolumn{1}{|c|}{ Hipotezler } & Yol Katsayıs1 & Kabul/Ret \\
\hline H1 & Platform Bilinirliği $\rightarrow$ Platforma Güven & 0.083 & Kabul \\
\hline H2 & Platform Ünü $\rightarrow$ Platforma Güven & 0.822 & Kabul \\
\hline H3 & Platform Ünü $\rightarrow$ Hizmet Sağlayıcılarına Güven & 0.183 & Kabul \\
\hline H4 & Güven Eğilimi $\rightarrow$ Platforma Güven & 0.026 & Kabul \\
\hline H5 & Güven Eğilimi $\rightarrow$ Hizmet Sağlayıcılarına Güven & 0.185 & Kabul \\
\hline H6 & Platforma Güven $\rightarrow$ Hizmet Sağlayıcılarına Güven & 0.593 & Kabul \\
\hline H7 & Platforma Güven $\rightarrow$ Paylaşım Hizmetini Kullanma Niyeti & 0.604 & Kabul \\
\hline H8 & $\begin{array}{l}\text { Hizmet Sağlayıcılarına Güven } \rightarrow \text { Paylaşım Hizmetini Kullanma } \\
\text { Niyeti }\end{array}$ & 0.194 & Kabul \\
\hline
\end{tabular}

Tablo 5' e göre platform bilinirliğinin, platform ününün ve genel güven eğiliminin, platforma güveni pozitif ve anlamlı şekilde etkilediği bulunmuştur. Ayrıca platform ününün ve genel güven eğiliminin, hizmet sağlayıcısına olan güveni pozitif ve anlamlı şekilde etkilediği görülmüştür. Platforma güvenin ise, hizmet sağlayıcısına olan güveni ve paylaşım hizmetini kullanma niyetini pozitif ve anlamlı şekilde etkilediği bulunmuştur. Son olarak hizmet sağlayıcısına olan güvenin, paylaşım hizmetini kullanma niyetini pozitif ve anlamlı şekilde etkilediği bulunmuştur.

Sonuç olarak araştırma modelinde yer alan tüm değişenlerin paylaşım hizmetini kullanma niyeti üzerinde pozitif ve anlamlı etkileri olduğu görülmüştür. Kavramsal/kuramsal çerçevede ortaya koyulan araştırma modeli ve araştırma hipotezleri kabul edilmiştir. 


\section{Sonuç ve Tartışma}

Bu çalışmada çevrimiçi veya mobil paylaşım hizmetlerine katılımı etkileyen güven faktörlerinin belirlenmesi amaçlanmıştır. Bu amaç doğrultusunda, önerilen kuramsal modeli test etmek için Yapısal Eşitlik Modeli(YEM) yaklaşımı kullanılmıştır. Araştırma modelinin testi için Airbnb paylaşım hizmeti seçilmiştir. Smart PLS 3.0 programı ile araştırma modeli test edilmiştir

Airbnb 'ye katılımı etkileyen güven faktörlerinin tüketiciler açısından ele alındığı model Airbnb kullanma niyetinin \%59 'unu açılamaktadır ( $\left.\mathrm{R}^{2}=0.59\right)$. Bu durum, Airbnb bilinirliğinin, Airbnb platformuna olan güvenin, Airbnb platformunun ününün, genel güven eğiliminin ve mülk sahibine olan güvenin, Airbnb'yi kullanma niyeti üzerinde güçlü ve istatiksel olarak anlamlı etkisi olduğunu göstermektedir.

Çevrimiçi veya mobil paylaşım hizmetlerine duyulan güven, paylaşım ekonomisine katılımı nasıl etkiler? sorusu araştırmanın temel problemidir. Ve yapılan analizler sonucunda çevrimiçi veya mobil paylaşım hizmetlerine duyulan güven paylaşım ekonomisine katılımı pozitif ve anlamlı olarak etkilediği bulunmuştur.

Türkiye'de uluslararası markalaşmış veya ünü olan platformlara olan güvenin yüksek olmasına karşın o markaya hizmet veren hizmet sağlayıcılarına güvenin görece düşük olduğu gözlemlenmiştir. Bu durum Türkiye'de paylaşım hizmetleri faaliyetleri yapacak firmaların, hizmet sağlayıcılara da güveni kazanmak adına sistemlerinde güven artırıcı önlemler almaları gerektiğini ortaya koymaktadır.

Mevcut literatürde paylaşım ekonomisiyle ilgili sınırlı sayıda çalışma yapılmıştır. Bu çalışma, dijital ortam ile paylaşım hizmetlerinin birbiri ile ilişkisini güven boyutunda ele alması yönüyle sınırlı çalışmalardan biri olarak katkıda bulunacaktır. Ayrıca çalışmanın, yeni ekonomik sistem hakkındaki bilimsel eksiklikleri de doldurması beklenmektedir.

Her çalışmada olduğu gibi bu çalışmanın da belli kısıtlar altında geçerliliği değerlendirilmelidir. Yeni bir sistemin kabulünde etkili olan birçok faktör bulunmaktadır. Bu çalı̧̧ma, çevrimiçi veya mobil paylaşım hizmetlerinin kabulünde ve kullanımında kullanıcıyı etkileyen faktörleri sadece güven faktörü ile sınırlı tutmaktadır. Paylaşım hizmetlerinin kabulünde etkili olabilecek başka faktörlerin incelenmesi ve tüm paylaşım uygulamalarının dahil edilerek kapsamlı bir araştırma yapılması diğer çalışmalara bırakılmışır. Araştırmanın bir diğer kısıtı ise, güven duygusunun anlık değişen soyut bir olgu olmasıdır. Tecrübe ve deneyimler ile güven düzeyi zamanla değişebilir. Bu çalışma 05.01.2019 tarihi ile 10.04.2019 tarihleri arasında bireylerin güven algısını ölçmüştür.

Model üzerinde sınanan hipotezler sadece nicel yöntem analizleri kullanılarak test edilmiştir. Araştırmacılar bu hipotezleri ayrıca nitel araştırma yöntemlerini kullanılarak yeniden araştırıp inceleyebilirler. Araştırma kapsamında modelin başka paylaşım hizmetlerinde de test edilmesinin, sonuçların karşılaştırılması açısından faydalı olacağı düşünülmektedir. Ek olarak farklı kültürler dâhil edilerek farklı örneklemler üzerinden kültürlerarası karşılaştırma yapılması gelecek çalışmalar için önerilmektedir.

Sonuç olarak, bu çalışma, dijital ortam ile paylaşım hizmetlerinin birbiri ile ilişkisini güven boyutunda ele alması yönüyle sınırlı sayıdaki çalışmalardan birisi oluşturmaktadır. Bu çalışma paylaşım hizmetlerinin benimsenmesi ile ilgili çalışmalara örnek teşkil edecektir ve gelecek çalışmalar için kaynak niteliğindedir.

\section{Kaynaklar}

Airbnb. (2018). Hakkımızda - Airbnb Basın Odası. Erişim Tarihi: 18 Ekim 2018, link: https://press.airbnb.com/about-us/

Altunışık, R., Coşkun, R., Bayraktaroğlu, S. \& Yıldırım, E. (2002). Sosyal Bilimlerde Araştırma Yöntemleri SPSS Uygulamaları - Sakarya: Sakarya Kitabevi.

Ateş, V. (2014). Üniversitelerin Bilişim Teknolojileri Risk Yönetimi Başarısını Etkileyen Faktörlerin Yapısal Eşitlik Modeli İle Modellenmesi.

Bart, Y., Shankar, V., Sultan, F., \& Urban, G. L. (2005). Are the Drivers and Role of Online Trust the Same for All Web Sites and Consumers?: A Large-Scale Exploratory Empirical Study. Journal of Marketing, 69, 133-152. https://doi.org/10.2139/ssrn.380404 
T. Aslan - A. Akbiyık 11/3 (2019) 2322-2332

Belk, R. (2014). You are what you can access: Sharing and collaborative consumption online. Journal of Business Research, 67(8), 1595-1600. https://doi.org/10.1016/j.jbusres.2013.10.001

Botsman, R. (2013). The sharing economy lacks a shared definition. Fast Company, 1-8. https://doi.org/http://www.fastcoexist.com/3022028/the-sharing-economy-lacks-a-shared-definition\#10

Botsman, R., \& Rogers, R. (2010). What's mine is yours : the rise of collaborative consumption. Harper Business.

Chung, K., Shin, J., (2010) "The antecedents and consequents of relationship quality in internet shopping", Asia Pacific Journal of Marketing and Logistics, Vol. 22 Issue: 4, pp.473-491, https:// doi.org/10.1108/13555851011090510

C,okluk, O., Sẹkercioglu, G., \& Büyuiköztürk, S. (2010). Sosyal bilimler için çok değı̆şkenli istatistik: SPSS ve LISREL uygulamaları. Pegem Akademi.

Davis, P. (2012). Trust is \#1 Barrier to Sharing | Deskmag | Coworking. Erişim Tarihi: 14 Kasım 2018, http://www.deskmag.com/en/trust-is-1-barrier-to-sharing-coworking-shareable-491

Demircan, N., \& Ceylan, A. (2003). Örgütsel Güven Kavram : Nedenleri ve Sonuçlar. Yönetim ve Ekonomi, 10(2). Erişim Tarihi: 8 Kasım 2018, http://webcache.googleusercontent.com/search?q=cache:http://www2.bayar.edu.tr/yonetimekonomi/d ergi/pdf/C10S22003/ndac.pdf

Forbes. (2018). Airbnb made $\$ 93$ million in profit on $\$ 2.6$ billion in revenue, but an internal clash sent the CFO out the door. Erişim Tarihi: 25 Kasım 2018, https://www.forbes.com/sites/greatspeculations/2018/05/11/as-a-rare-profitable-unicorn-airbnbappears-to-be-worth-at-least-38-billion/\#405bdb8e2741

Gao, S., Jing, J., \& Guo, H. (2017). The Role of Trust with Car-Sharing Services in the Sharing Economy in China: From the Consumers ' Perspective.

Gefen, D. (2000). E-commerce: the role of familiarity and trust. 28, 725-737. https://doi.org/10.1016/S03050483(00)00021-9

Gefen, D., \& Straub, D. W. (2004). Consumer trust in B2C e-Commerce and the importance of social presence: Experiments in e-Products and e-Services. Omega, 32(6), 407-424. https://doi.org/10.1016/j.omega.2004.01.006

Giffin, K. (1967). The contribution of studies of source credibility to a theory of interpersonal trust in the communication process. Psychological Bulletin, 68(2), 104-120. http://dx.doi.org/10.1037/h0024833

Gürbüz, S., \& Şahin, F. (2016). Sosyal Bilimlerde Araştırma Yöntemleri. Seçin Yayıncılık.

Hamari et al. (2015). The Sharing Economy: Why People Participate in Collaborative Consumption. Communications in Information Literacy, 1-13. https://doi.org/10.1002/asi

Hou, L. (2018). Destructive sharing economy: A passage from status to contract. Computer Law and Security Review, 34(4), 965-976. https://doi.org/10.1016/j.clsr.2018.05.009

Jarvenpaa, S. L., Tractinsky, N., \& Saarinen, L. (2000). Consumer Trust in an Internet Store: A Cross-Cultural Validation. Journal of Computer-Mediated Communication, 5(2), 0-0. https://doi.org/10.1111/j.10836101.1999.tb00337.x

Jones, K., \& Leonard, L. N. K. (2008). Trust in consumer-to-consumer electronic commerce. https://doi.org/10.1016/j.im.2007.12.002

Kim, D. J., Ferrin, D. L., \& Rao, H. R. (2009). Trust and Satisfaction, Two Stepping Stones for Successful ECommerce Relationships: A Longitudinal Exploration. Information Systems Research, 20(2), 237-257. https://doi.org/10.1287/isre.1080.0188

Kim et al. (2015). Why people participate in the sharing economy: A social exchange perspective. PACIS 2015 Proceedings (Paper 76), Paper 76. 
T. Aslan - A. Akbiyık 11/3 (2019) 2322-2332

Kosintceva, A. (2016). Business Models Of Sharing Economy Companies. Master Thesis In International Business.

Koufaris, M., \& Hampton-Sosa, W. (2004). The development of initial trust in an online company by new customers. Information and Management, 41(3), 377-397. https://doi.org/10.1016/j.im.2003.08.004

Liang, T. P., \& Lai, H. J. (2002). Effect of store design on consumer purchases: An empirical study of on-line bookstores. Information and Management, 39(6), 431-444. https://doi.org/10.1016/S0378-7206(01)00129-X

Liao, Z., \& Cheung, M. T. (2002). Internet-based e-banking and consumer attitudes: an empirical study. Information \& Management, 39(4), 283-295. https://doi.org/10.1016/S0378-7206(01)00097-0

Mair, J., \& Reischauer, G. (2017). Capturing the dynamics of the sharing economy: Institutional research on the plural forms and practices of sharing economy organizations. Technological Forecasting and Social Change, 125 (July 2016), 11-20. https://doi.org/10.1016/j.techfore.2017.05.023

Moorman, C., Deshpandé, R., \& Zaltman, G. (1993). Factors Affecting Trust in Market Research Relationships. In Source: Journal of Marketing (Vol. 57). Erişim Tarihi: 3 Ekim 2018, https://faculty.fuqua.duke.edu/ moorman/Publications/JM1993.pdf

Mun, J. M. (2013). Online Collaborative Consumption: Exploring Meanings, Motivations, Costs, And Benefits.

Oxford Dictionary. (2018). sharing economy I Definition of sharing economy in English by Oxford $\begin{array}{lllll}\text { Dictionaries. } & \text { Erişim } & \text { Tarihi: } & 17 & \text { Kasım }\end{array}$ https://en.oxforddictionaries.com/definition/sharing_economy

Öngel, G. (2018). Sağlık Çalışanlarının Yaşamış Oldukları İş-Aile Yaşamı Çatışmasının Örgütsel Bağlllık, İş Doyumu Ve İsten Ayrulma Niyetine Etkisi.

Parente et al. (2018). The Sharing Economy Globalization Phenomenon: A Research Agenda. Journal of International Management, 24(1), 52-64. https://doi.org/10.1016/j.intman.2017.10.001

PwC. (2015). The sharing economy: how is it affecting you and your business? PwC, (January), 1-10. Erişim Tarihi: 15 Kasım 2018, http://pwc.blogs.com/files/sharing-economy-final_0814.pdf

Ratnasingam, P. (2004). Trust in inter-organizational exchanges: a case study in business to business electronic commerce. https://doi.org/10.1016/j.dss.2003.12.005

Statista. (2018a). Number of Airbnb users US/Europe 2015-2020 | Statistic. Erişim Tarihi: 8 Ekim 2018, https://www.statista.com/statistics/795877/number-of-airbnb-users/

Statista. (2018b). Value of the global sharing economy 2014-2025 | Statistic. Erişim Tarihi 8 Ekim 2018, https://www.statista.com/statistics/830986/value-of-the-global-sharing-economy/

Tosuner, A. (2012). Tüketim Davranışının Azaltılması için İnternetin Kullanılması: Ortak Kullanım Ağları. XVII. Türkiye'de Internet Konferansi.

Weisberg, J., Te'eni, D., \& Arman, L. (2011). Past purchase and intention to purchase in e-commerce: The mediation of social presence and trust Article information. 21(1), 82-96. https://doi.org/10.1108/10662241111104893

Ye, C. (2013). Toward an integrated understanding of online trust. Erişim Tarihi: 11 Kasım 2018, https://vpn.utm.my/docview/1448297657?accountid=41678

Zvolska, L. (2015). Sustainability Potentials of the Sharing Economy: The case of accommodation sharing platforms. Erişim Tarihi: 24 Ekim 2018, http://lup.lub.lu.se/studentpapers/record/8055286\%0Ahttps://lup.lub.lu.se/student-papers/search/publication/8055286 